\title{
Os usos que o psicótico faz da droga
}

The uses a psychotic subject makes of drugs

Los usos que el sujeto psicotico hace de las drogas

\author{
Helena Greco Lisita* \\ Márcia Maria Vieira Rosa
}

\begin{abstract}
Resumo
O objeto de pesquisa deste trabalho é a interface entre toxicomania e psicose. A clínica atual revela grande número de sujeitos psicóticos usuários de drogas ilícitas, o que nos leva a pensar a parceria entre o psicótico e a droga como um dos modos de entrelaçamentos que a psicose mantém com a atualidade. Parte-se da hipótese de que o uso da droga na psicose não pode ser pensado da mesma forma que na neurose. Se, na neurose, a toxicomania é relacionada à ruptura com o gozo fálico que leva a um uso sem limites e sem significação da droga, na psicose essa ruptura é dada de antemão, já que se trata de uma condição estrutural, decorrente da foraclusão do significante Nome-do-pai. Assim, a droga, na psicose, parece ter caráter bem delimitado, exercendo função específica: o tratamento do gozo sem significação que invade o sujeito.
\end{abstract}

Palavras-chave: psicose; toxicomania; uso; droga; gozo.

\begin{abstract}
This paper focuses on the interface between toxicomania and psychosis. The general practice has revealed a growing number of psychotic subjects who are users of illicit drugs, which leads us to reflect upon the partnership between the psychotic and the drug as a facet of the interweaving of psychosis and the modern world. We start with the hypothesis that the use of the drug in psychosis cannot be thought of in the same way as in neurosis. While toxicomania in neurosis is related with the rupture with phallic jouissance, leading to a usage without limits and signification of the drug, in psychosis this rupture is given beforehand: it is a structural condition caused by the foreclosure of the Name-of-the-Father significant. As a result, the drug in psychosis seems
\end{abstract}

\footnotetext{
Mestra em Teoria Psicanalítica pela Universidade Federal de Minas Gerais (UFMG), psicóloga. E-mail: helenagreco@ globo.com.

** Pós-doutora em Teoria Psicanalítica pela Universidade Federal do Rio de Janeiro (UFRJ), doutora em Literatura Comparada pela Universidade Federal de Minas Gerais (UFMG), psicóloga, psicanalista, membro da Escola Brasileira de Psicanálise (EBP) e da Associação Mundial de Psicanálise (AMP), professora do Programa de Pós-graduação em Psicologia da Universidade Federal de Minas Gerais (UFMG). E-mail: márcia.rosa@globo.com.
} 
to have a clear character related to a very specific function: the treatment of the jouissance without signification that invades the subject.

Keywords: psychosis; toxicomania; usage; drug; jouissance.

\section{Resumen}

Este trabajo trata de la interfaz entre el uso indevido de drogas y la psicosis. La clínica actual revela un número creciente de psicóticos que hacen uso de drogas ilícitas, lo que nos lleva a pensar la asociación entre el psicótico y las drogas como uno de los modos de ligación que la psicosis mantiene con la actualidad. Se parte de que el uso de drogas en la comprensión de la psicosis difiere de la comprensión de la neurosis: si en la neurosis está relacionado a la ruptura con el gozo fálico y esto conduce a un uso sin límites y significado de drogas, en la psicosis esta ruptura se da con antelación porque es resultante de una condición estructural, consecuencia de la foraclusión de Nombre-del Padre. Por lo tanto, la droga en psicosis, parece estar relacionada con una función muy específica, a saber, el tratamiento del gozo sin significación que invade al sujeto.

Palabras clave: psicosis; toxicomania; uso; drogas; gozo.

\section{Introdução}

- xperiências clínicas na área da saúde mental mostram um grande número de pacientes psicóticos usuários de drogas ilícitas. O cotidiano da clínica atual revela situações em que o recurso à droga se constitui em uma tentativa fracassada de tratamento do gozo, uma vez que provoca efeitos tão devastadores sobre os sujeitos quanto os da própria psicose (Carvalho, 2005). Tal fato levanta a hipótese de que a toxicomania, ou o consumo regular de drogas, pode estar hoje se constituindo em uma "solução psicótica contemporânea" (Benetti, 1998, p. 219). Assim, é possível pensar a parceria entre o psicótico e a droga como uma faceta dos entrelaçamentos que a psicose mantém com a atualidade.

A adição à droga pode obscurecer, por algum tempo, a questão diagnóstica. Esse é um aspecto delicado do tratamento com psicóticos que fazem uso regular de drogas ilícitas e aponta para a extrema importância da localização da função da droga para o sujeito na determinação do diagnóstico diferencial. 
Vale ressaltar que o interesse em investigar e discutir as possíveis relações entre psicose e toxicomania parece recente, fruto de uma situação atual imposta à clínica psicanalítica. Não é possível encontrar nas obras de Freud e Lacan trabalhos que discutam especificamente esse tema. Esse fato, no entanto, não inviabiliza que o tema proposto seja objeto de investigação psicanalítica e que a utilização de noções introduzidas pela psicanálise torne viável a articulação entre toxicomania e psicose.

A hipótese levantada aqui é de que o uso da droga não pode ser pensado da mesma forma no campo da psicose e da neurose. Enquanto, na neurose, a toxicomania é relacionada ao uso desregulado, sem limites e sem significação da substância tóxica, na psicose o uso da droga parece ter um caráter bem delimitado, relacionado a uma função bem específica.

Para introduzir a discussão do tema aqui proposto, será apresentado, a seguir, fragmento de um caso clínico referente a um sujeito psicótico usuário de drogas, atendido em um hospital da rede pública de Belo Horizonte. Tratase de um sujeito de 49 anos, solteiro, desempregado e, aqui, denominado Marcelo.

\section{Marcelo e o uso de substâncias químicas}

Marcelo procurou o serviço de Psicologia de um hospital-geral de Belo Horizonte, do qual eu fazia parte, solicitando atendimento. Ele acompanhava um irmão hospitalizado que exigia cuidados constantes. No primeiro atendimento, contou que já havia passado por várias internaçôes em hospitais psiquiátricos. Relatou que, aos 16 anos, começou a escutar vozes que o deixavam muito nervoso. Não soube falar sobre o primeiro surto nem sobre a primeira internação. Afirmou que ainda escutava vozes, embora com menos frequência. Contou também que tinha visões, via bichos em sua cama. Disse que tinha "delírios", ficava "imaginando coisas engraçadas na cabeça e rindo sozinho".

Relatou fazer uso de drogas desde os 16 anos e afirmou que esse uso foi posterior ao primeiro surto. Usou maconha por muito tempo, depois cocaína e crack. Na época da conversa, gostava apenas de usar crack e bebia cachaça com frequência. Disse que, quando usava droga, sentia-se "anestesiado", as vozes desapareciam: "A cabeça fica mais calma, pensando menos". Afirmava que, às vezes, passava cerca de um mês sem usar drogas, mas, por algum motivo que não sabia explicar, ficava "dominado" e voltava a usar drogas novamente. Disse que precisava parar de usar drogas porque estava ficando velho: "Preciso ser 'careta' como as pessoas da minha idade". No entanto, afirmava que gostaria de 
ter dinheiro suficiente para comprar seu próprio apartamento, onde pudesse "fumar, usar drogas e beber uisque à vontade".

Ele disse que estava fazendo uso de crack de forma mais restrita, pois não tinha dinheiro para comprá-lo sempre. Ele recebia meio salário mínimo de benefício, que usava para comprar refrigerante, cigarro, cachaça e, eventualmente, crack. Contou que conhecia alguns usuários de crack que moravam perto da casa dele e que frequentemente esses lhe ofereciam "uma ponta de mesclado" (mistura de maconha e crack) se ele fosse até a "boca de fumo" buscar droga. Assim, ele conseguia usar droga, mesmo que não tivesse dinheiro para comprá-la. Disse que não tinha amigos, apenas conhecia algumas pessoas com as quais saía para fazer uso de drogas. Devido ao uso constante de drogas, Marcelo frequentava ambiente marginal, conhecia ladrões e traficantes.

Marcelo disse ter me procurado porque ele estava usando drogas com frequência e não conseguia parar. Afirmou ser muito difícil, pois ele ficava "possuído" e não conseguia ficar sem a droga. "Às vezes, se alguém me ajudar, eu consigo largar."

Durante os atendimentos, ele passava a maior parte do tempo falando sobre sua relação com as drogas. Disse não ter interesse por quase nada. "Gosto mesmo é de beber cachaça e fumar crack."

Segundo Marcelo, o uso constante de Haldol diminuía a vontade de beber. Ele fazia acompanhamento psiquiátrico mensal em posto de saúde e estava fazendo uso de Haldol Decanoato e Akineton. "Eu gosto mesmo de tomar é o Akineton, porque ele me deixa anestesiado, como se eu tivesse tomado droga." Contou, então, que fazia uso errado de Akineton, tomando doses muito superiores às prescritas pelo médico. Por isso, a medicação que recebia no posto de saúde acabava muito antes do previsto (ele recebia quantidade para ser tomada durante um mês). Como não tinha dinheiro e nem receita médica para comprar mais remédio, ele recorria a um conhecido que também fazia uso da medicação.

Ele nunca contara ao médico que fazia uso abusivo da medicação e disse não ver nenhum problema nisso: "É remédio, acho que não deve fazer mal tomar a mais, meu corpo já está costumado". Em seguida, falou que, se não

\footnotetext{
Haldol Decanoato é o nome comercial do haloperidol decanoato (injetável), um neuroléptico do grupo das butirofenonas indicado para tratamento dos sintomas psicóticos, que pode causar reações neurológicas do tipo extrapiramidal. Na maioria dos pacientes, essas reaçôes envolvem sintomas1 do tipo parkinsoniano (rigidez, tremor, bradicinesia e instabilidade postural). Akineton é o nome comercial do cloridrato de biperideno, indicado para tratamento do parkinsonismo e das reaçôes adversas extrapiramidais induzidas pelos neurolépticos e outras drogas que bloqueiam receptores basais de dopamina e também criam uma deficiência funcional de dopamina (Anvisa. Bulário Eletrônico. Recuperado de: <http://bulario.bvs. br/index.php> em novembro de 2009).
} 
tomasse muito Akineton, começava a "delirar". Sobre esses "delírios", disse: "Fico só quieto num canto, pensando coisa e rindo sozinho". Acreditava que esses "delírios" aconteciam por causa do "cheirinho de loló" que usava quando era adolescente: "Algum músculo do meu nariz se expande, ai eu sinto o cheiro do loló de novo e começo a delirar", afirmou.

Em alguns momentos, demonstrava desejo de parar de usar drogas. Contou que ficara muito assustado com a morte de um conhecido, usuário de drogas, que morava perto de sua casa: "Deve ter sido traficante que matou; eu tenho que parar de mexer com isso". Contou que usava crack desde que a droga se tornou conhecida e acessível na cidade. Usava com mais frequência, pois a droga era mais barata. Segundo ele, foi muito difícil diminuir o uso, mas não tinha dinheiro para usar tanto quanto gostaria. Acreditava, ainda, que tinha feito menos uso de drogas por causa da idade, ainda assim, disse que, às vezes, precisava muito de usar drogas: "Sinto muita dor de cabeça, parece que a cabeça para, o pensamento paralisa, ai dá vontade de usar drogas ou beber cachaça. Enquanto não uso, isso não para".

Durante um atendimento, contou-me, um pouco envergonhado, que fumara maconha no dia anterior. "Foi por hábito mesmo, nem fumei muito porque tinha muita gente pra dividir. O pessoal tá lá fumando, eu só não vou fumar se eu for bobo." Em seguida, contou que, certa vez, estava em um bar e escutou alguém dizer: "Quem não gosta de tomar cachaça é bobo". Marcelo riu e disse: "É, eu é que não sou bobo".

Nesse mesmo atendimento, Marcelo me perguntou se psicólogo poderia receitar remédio, assim como o médico. Respondi que não e questionei o motivo da pergunta que ele me fizera. Ele disse que, se eu pudesse receitar, ele iria me pedir uma injeção de Akineton para "ficar mais ligado, mais anestesiado".

Uma semana após esse atendimento (que deveria ter sido o último, pois o irmão de Marcelo teria alta, e eu não poderia mais atendê-lo no hospital) encontrei Marcelo no corredor do hospital. Ele estava trazendo o irmão para assistir à missa. Estava nitidamente embriagado. Contou que estava sem o Akineton e por isso estava bebendo havia três dias seguidos. Afirmou que, em breve, pegaria a medicação no posto de saúde e então poderia parar de beber. Perguntei se ele gostaria de voltar ao hospital na semana seguinte para conversarmos um pouco, e ele aceitou minha proposta.

Marcelo retornou ao hospital no dia marcado. Estava lúcido e contou que foi ao Posto de Saúde no dia anterior tomar Haldol. "Se eu não tivesse tomado, não teria conseguido vir aqui hoje. Sem o remédio, fico muito desanimado." 
Contou que, antes de tomar o Haldol, fizera uso de crack. "Mas agora, com o Akineton, dá pra ficar sem usar. Não dá vontade nem de beber porque me deixa animado, com vontade de sair." Além disso, afirmou que parava de sentir "as coisas no corpo". Segundo ele, quando estava lúcido ou sem fazer uso do Akineton, sentia "a pele queimando". Acreditava que essa sensação era decorrente de uma surra que levara do pai quando tinha 13 anos. Sobre essa surra, limitou-se a dizer que apanhou por ter passado muito tempo trancado no banheiro. Quando perguntei a ele o que estava fazendo dentro do banheiro, ele respondeu que não se lembrava e começou a rir. Ficou então a suposição de que ele estaria se masturbando.

Marcelo disse que voltaria ao hospital para levar o irmão a um retorno e perguntou se poderia atendê-lo nesse dia. Afirmei minha disponibilidade e, na semana seguinte, o atendi novamente. Ele chegou dizendo: "Pensei em nem vir aqui conversar com você, mas resolvi na última hora aparecer". Ele estava bastante agitado, falando rápido, movimentando-se muito. Contou que havia tomado quatro comprimidos de Akineton naquele dia. Em seguida, riu e disse: "Não foi quatro não, foi sete". Falou que "exagerou" na dose porque tivera muita vontade de beber e estivera fumando "mesclado com frequência". Contou ainda que, em dez dias, havia tomado quase todos os comprimidos de biperideno, fornecidos para todo o mês.

Durante várias vezes nesse atendimento, Marcelo perdia o raciocínio, interrompia o que estava dizendo e dizia que não se lembrava mais do que diria. Mostrou-se preocupado por estar se drogando com frequência. Disse que o irmão sugerira que ele fizesse alguma atividade que o distraísse e desviasse sua atenção das drogas. "Mas não adianta, não tem jeito. Ultimamente não gosto de fazer nada, só mesmo de fumar droga."

Ele aceitou voltar ao hospital na semana seguinte, para novo atendimento, mas não compareceu. Após alguns dias, saí da instituição. Conversei com colegas e pedi a eles que acolhessem Marcelo caso ele retornasse ao hospital. No entanto, até meu último contato com esses colegas do hospital, isso não havia acontecido.

O caso clínico apresentado levanta uma série de questionamentos acerca da relação entre psicose e toxicomania. É possível falar de toxicomania nesse caso? Ou seria mais prudente pensar que a droga desempenha um papel bastante específico na vida desse sujeito? E qual seria, então, a função da droga nesse caso? Teria Marcelo encontrado na droga uma forma de autotratamento? O que pensar sobre a relação que ele estabelecia com a medicação psiquiátrica? 


\section{Função da droga na psicose}

Em 1975, Lacan definiu a droga como a única forma de romper o matrimônio do corpo com o gozo fálico. ${ }^{2}$ Essa tese parece ter se consolidado como norteadora no tratamento analítico das toxicomanias. Como afirma Laurent (1994), além de localizar o uso da droga como formação de ruptura com o gozo fálico, marca a ruptura com as particularidades da fantasia e da castração, e aponta o surgimento de um "gozo uno", que, diferente do gozo sexual, não é fragmentado. No entanto, Miller (1992) chama atenção para o fato de que essa afirmação de Lacan não serve como uma definição para a toxicomania, sendo somente uma tentativa de definir a droga em seu uso. Tal fato ressalta, portanto, que, na experiência analítica, pergunta-se menos pela toxicomania do que pela relação que o sujeito estabelece com a droga.

Fica claro que, segundo a psicanálise, a toxicomania não está ligada a nenhuma estrutura clínica em particular. Tal como observa Laurent (1994), o uso de drogas introduz a noção de ruptura com o gozo fálico, o que, no entanto, é insuficiente para definir uma estrutura clínica. A expressão ruptura com o gozo fálico foi utilizada por Lacan para se referir também à psicose, em que o Nome-do-pai não opera. O uso da droga aponta, portanto, para a possibilidade de uma ruptura com o gozo fálico, sem que haja necessariamente foraclusão do Nome-do-pai, desvinculando, assim, a noção de toxicomania à de estrutura clínica. Sendo assim, é possível pensar que, se por um lado, o recurso às drogas, tanto na neurose quanto na psicose, refere-se à posição do sujeito com relação ao Outro e ao gozo, por outro existem particularidades que diferem o uso da droga em cada situação. Na neurose, o uso da droga permite ao sujeito experimentar um novo modo de gozo, um gozo cínico que rechaça o Outro, que recusa que o gozo do próprio corpo seja metaforizado. A droga entra no lugar de uma tentativa de prescindir do Outro, na dimensão do autoerotismo. É uma forma de "curto-circuito", ou seja, uma forma de desvio do desejo do Outro, da castração do Outro (Miller, 1992). Na psicose, por sua vez, a droga parece ocupar um lugar diverso, bem delimitado.

Laurent (1994), ao falar da toxicomania na psicose, questiona a validade da tese proposta por Lacan de que a droga seria aquilo que permite romper o matrimônio com o falo. Na psicose, não é possível falar da droga como ruptura, uma vez que essa ruptura é dada de antemão, é uma condição

\footnotetext{
No original, em Frances: "[... il n'y a aucune autre défnition de la drogue que celle-ci : c'est ce qui permet de rompre le mariage avec le petit-pipi". Lacan propõe essa teoria no texto intitulado "Intervenção no encerramento das jornadas de cartéis", de 1975. Recuperado de <http://www.ecolelacaniane.net> em junho de 2009.
} 
estrutural, observa ele. $\mathrm{Na}$ psicose, há uma ruptura radical com o falo. $\mathrm{Ou}$ seja, não há falha, mas sim ausência da inscrição fálica, consequência da foraclusão do significante Nome-do-pai.

Há ainda outro ponto levantado por Laurent (1994): casos de psicose nos quais se observa o uso da droga com certo limite, certo controle e que diferem totalmente do uso maníaco descontrolado de uma ou várias drogas. São sujeitos que tomam drogas, mas que, apesar de se apresentarem sob o rótulo "sou toxicômano", estabelecem uma relação com a droga bastante particular, o que leva a questionar se realmente se trata de sujeitos toxicômanos. $\mathrm{O}$ autor assinala que esse uso limitado encaixa-se perfeitamente na categoria de monomania, apontando para um paradoxo, uma vez que se trata de uma mania, porém limitada, vinculada a uma determinada substância.

Percebe-se, portanto que, nos casos relacionados à monomania, o uso da droga não poderia ser pensado como tentativa de sair do campo do Outro, mas, ao contrário, como uma tentativa de restituir certo lugar ao Outro, à realidade. Esse é um ponto que difere significativamente o uso da droga na psicose, com uma função bem determinada, do uso compulsivo da droga na toxicomania verdadeira (Zaffore, 2005).

Por outro lado, o uso maníaco da droga pode ser encontrado em qualquer estrutura e, sendo assim, é possível encontrar sujeitos psicóticos que se drogam de forma descontrolada. Desse modo, a mania é um aspecto que pode confundir ou dificultar o diagnóstico diferencial entre neurose e psicose, uma vez que se encontra no polo oposto ao falo. Vale ressaltar que o falo é um regulador, uma medida, sendo capaz de contabilizar o gozo, enlaçando real e simbólico.

Em relação ao uso de drogas na psicose, é possível pensar em duas vertentes e vale assinalar que, embora sejam vias frequentemente observadas na prática clínica, não são únicas e esgotáveis. São modalidades de tratamento possíveis aos efeitos de invasão de gozo, que respondem precisamente a dois modos de retorno do gozo: a identificação do gozo no lugar do Outro e o retorno do gozo no próprio corpo (Naparstek, 2005). Dessa forma, pode-se mencionar uma via identificatória, na qual a droga permite algum tipo de enlace com o Outro, no nível do imaginário. $\mathrm{O}$ sujeito se identifica com o significante toxicômano e, de alguma forma, consegue estabelecer laço com o Outro. Trata-se, portanto, de uma tentativa de localizar parte do gozo no campo do Outro, uma tentativa de fazer um laço com o Outro a partir do gozo. Localizar o gozo permite 
apaziguá-lo, e a identificação com um significante, via consumo, pode ter a função de produzir um enlaçamento (Galante \& Naparstek, 2008).

A outra via diz respeito aos efeitos químicos produzidos pela droga. Efetivamente, é possível constatar que o uso da droga na psicose não produz necessariamente um excesso de gozo. Ao contrário, em alguns casos, serve como forma de limitar o gozo que invade o corpo do sujeito, produzindo um enlace com o Outro, ainda que precário. Como não há trabalho simbólico sobre a invasão de gozo, o que resta é o "tratamento do real pelo real" (Galante \& Naparstek, 2008, p. 146) por meio da ingestão da droga. Nesses casos, o uso da droga pode ser entendido como forma de buscar moderação, localização do gozo que invade o sujeito e que não pode ser regulado pelo discurso. Nesse sentido, a droga é usada, muitas vezes, para amenizar as vozes e pensamentos que invadem o sujeito ou para justificar a presença de fenômenos psicóticos. $\mathrm{O}$ recurso à droga é, portanto, uma tentativa de fazer da significação enigmática do gozo uma significação consistente: "é por causa da droga". Assim, o uso da droga e os efeitos por ela produzidos podem ser entendidos como uma resposta ao vazio de significação que acomete o sujeito. No entanto, essa se mostra uma solução precária e perigosa, já que o tratamento do real pelo real pode levar a uma verdadeira ruptura com o Outro, levando o sujeito à passagem ao ato.

Além dessas duas vertentes relacionadas ao uso da droga na psicose, é possível pensar em outro viés da toxicomania na psicose: a droga pode servir, em alguns casos, como uma suplência, sustentando um quadro fora do desencadeamento. Nesse sentido, é possível pensar nas psicoses ordinárias, em que o desligamento em relação ao Outro sobressai aos fenômenos elementares presentes na psicose desencadeada. Uma "suplência química", como afirma Beneti (1998, p. 219), que mais além da moderação de gozo funciona como uma "autopreservação ao delírio", impedindo o desencadeamento da psicose.

Não obstante, um dado comum observado na prática clínica aponta a possibilidade de desencadeamento de um surto psicótico após um período de suspensão do uso de substâncias tóxicas. Castanet e De Georges (2003) referem-se a casos frequentes de sujeitos psicóticos que permaneceram longos períodos assintomáticos em função do uso contínuo de drogas. Quando submetidos a tratamentos substitutivos, apresentavam o primeiro surto, com a presença de fenômenos elementares, característicos da psicose. Assim, esses sujeitos testemunham que o uso de drogas pode encobrir questóes pertencentes ao campo da psicose, sem que haja um desencadeamento típico. A droga serve como uma espécie de tampão em relação à divisão subjetiva. Ao interromper o uso da droga, o sujeito depara novamente suas questões e divisão subjetiva 
e, sem recursos simbólicos para se haver com isso, vivencia um surto psicótico.

Por fim, vale mencionar o desencadeamento de um surto psicótico provocado pelo uso de substâncias tóxicas. É possível, com frequência, associar o momento de ruptura do desencadeamento psicótico à experiência com a droga. Os efeitos produzidos pela droga podem colocar o sujeito diante de algo que ele é incapaz de nomear por falta de recursos simbólicos. Assim, existem os casos nos quais o sujeito relata jamais ter "voltado de uma viagem" provocada pelo uso da droga. Percebe-se, portanto, a complexidade de fatores presentes na clínica da psicose na atualidade, o que, sem dúvida, põe à prova a definição de diagnósticos e, consequentemente, a direção do tratamento, sobretudo nos casos em que o uso da droga se faz presente.

\section{Retorno ao caso clínico}

É possível perceber que Marcelo busca na droga algo bem específico, circunscrito, diferente do que se percebe na prática usual dos toxicômanos, estritamente ligada ao ato, desvinculada de qualquer sentido.

No seu caso, a droga cumpre uma função bem específica. Percebe-se claramente que ele utiliza a droga como uma forma de moderar o gozo que o invade, de amenizar os fenômenos elementares que o acometem. Quando usa a droga, sente-se anestesiado, as vozes tornam-se menos frequentes, ele deixa de sentir a queimação no corpo. É possível pensar que o efeito produzido pela droga, de certa forma, redireciona o gozo invasivo decorrente da alucinação. Ao mesmo tempo, parece dar certo sentido ao que Marcelo sente. As sensações no corpo ganham significação, são legitimadas pelo uso da droga.

É interessante pensar a marca da intervenção paterna no real do corpo desse paciente, que atribui a sensação de queimação no corpo a uma surra que levou do pai na adolescência. Essa queimação sugere algo da ordem do encontro com o pai, resgatado pela via do gozo. Laurent (2004, p. 37) afirma que o Édipo "permite a significação, a neutralização do gozo. Nesse sentido, ele é sublimação ou anestésico". Com base nisso, pode-se pensar que Marcelo, por sua condição estrutural, não pode fazer uso desse recurso do Édipo e, assim, busca na droga seu anestésico. As marcas de gozo no corpo, como a queimação, a experiência com o "cheirinho de loló" que retorna sobre o corpo, expandindo o músculo de seu nariz e o fazendo delirar, apontam para o gozo marcado pela 
ausência da significação fálica $(-\Phi)$, que retorna de forma enigmática sobre o corpo desse sujeito.

É possível, ainda, relacionar essa surra do pai ao texto de Freud "Uma criança é espancada". O pai é tido para Marcelo como um pai gozador, aquele que espanca. É evidente, no entanto, que, nesse caso, não se pode falar de uma fantasia, no sentido do texto freudiano. Como afirmam Maleval et al. (2009, p. 13), os cenários imaginativos dos sujeitos psicóticos não podem ser apreendidos tal como no campo da neurose e devem, portanto, ser distinguidos da fantasia fundamental $(\$ \diamond a)$, "motor da realidade psíquica do sujeito dividido" (2009, p. 14), que pressupõe uma extração do objeto a. A carência da fantasia fundamental pode ser entendida como uma das consequências essenciais da foraclusão do Nome-do-pai, e, portanto, a função de obturação do real, própria à fantasia fundamental, não opera nesse caso. No entanto, "o sujeito psicótico dispõe de inúmeras possibilidades para compensar essas faltas". Longe de aparentar inconsistência, alguns sujeitos mostram, ao contrário, ter fixado seu eu (moi) em identificações muito sólidas. Assim, essas identificações parecem funcionar como um "molde", um enquadre imaginário para o gozo. Tal fato pode ser associado à relação que Marcelo estabelece com a surra que levou do pai e que retorna sob a forma de queimação na pele, sensação essa que é anulada por meio do uso da droga.

Por outro lado, Marcelo se identifica com o sintagma "usuário de drogas". O uso de drogas permite que ele estabeleça, ainda que de forma bastante precária, relacionamentos sociais. Por meio de uma identificação imaginária, ele passa a se relacionar com outras pessoas, tem colegas com os quais sai para usar drogas e com os quais tem um traço em comum: a dependência pela droga. É interessante notar o deslizamento significante que permite a Marcelo assumir uma nova posição: se antes era tido como "doido", egresso de hospitais psiquiátricos, incapaz, sendo, portanto, discriminado pela família e vizinhos, ao usar drogas, ele assume um novo lugar, o de "doidão", nominação a partir da qual é capaz de "pensar melhor", de estabelecer vínculos sociais e de se reconhecer num papel bem definido.

O caso dá margem para se pensar a questão da monomania. Marcelo não utiliza qualquer tipo de droga nem bebe qualquer tipo de bebida. Ele elege a cachaça e o crack como substâncias de sua preferência, e se restringe ao uso delas. Por outro lado, o dinheiro é um elemento que limita o uso compulsivo de Marcelo, pois, por várias vezes, afirmou que, 
se tivesse mais dinheiro, consumiria mais. É também um fator que o leva a usar maconha em algumas ocasiōes, já que, muitas vezes, alguém lhe oferece "uma bola", ou seja, um trago, sem que ele precise comprar. No entanto, afirma que não gosta muito e, muitas vezes, consegue recusar a maconha, preferindo a cachaça. A falta de dinheiro poderia levá-lo a vender objetos pessoais ou da família a fim de obter dinheiro para comprar droga ou até mesmo a cometer furtos, fato muito comum a sujeitos toxicômanos. Entretanto isso não acontece. Tal fato demonstra que ele tem algum limite e, assim, doses relativamente pequenas das substâncias parecem ser suficientes para apaziguá-lo.

É possível pensar, ainda, que a escolha de Marcelo pela cachaça esteja ligada ao significante "bobo", tomado por ele de forma literal. Alguém, certa vez, disse-lhe que "Quem não toma cachaça é bobo", ao que ele respondeu "Eu é que não sou bobo". Esse fato confirma a hipótese de que o uso da droga, ou da bebida, confere a esse sujeito um lugar, uma identidade. Ele jamais recusa a cachaça se lhe é oferecida. Tal fato o tornaria um "bobo", colocando-o novamente na posição marginalizada do "doido".

A precariedade simbólica desse paciente pode ser percebida também na relação que ele estabelece com as doses utilizadas. Diz que já está velho para usar drogas, tanto quanto usava antigamente, o que não passa de uma reprodução da fala de sua mãe. Ele não elabora nada a partir disso, apenas reproduz, em sua fala, um desejo que é da mãe: que ele pare de usar drogas, arrume um emprego ou passe a desempenhar alguma atividade que lhe interesse. No entanto, a única coisa que ele consegue elaborar é "Não tem jeito, eu não gosto de nada, só de usar drogas mesmo".

Existe ainda um ponto que chama atenção no caso: a substituição da droga por um medicamento farmacológico. Marcelo faz uso do Akineton de forma incorreta; no entanto, por se tratar de uma medição farmacológica, prescrita por médico e legalmente aceita e vendida, ele não questiona o uso abusivo e a dependência em relação ao remédio. Parece claro, entretanto, que o Akineton passa a ocupar o mesmo lugar da droga na economia psíquica desse sujeito, sendo um exemplo clássico do uso "off label" do medicamento, tal como sugere Laurent (2008). É possível pensar que o uso "off label" da medicação na atualidade carrega em si a dimensão do pharmakón: aquilo que, a princípio, constituise como remédio, podendo trazer benefícios ao organismo, acaba por tornar-se um veneno, quando passa a ser usado de forma compulsiva, 
desordenada e desvinculada de sua função. O uso do Akineton extrapola os efeitos pretendidos (amenizar os efeitos extrapiramidais provocados pelo antipsicótico), passando a ser nocivo à saúde do paciente. Nesse sentido, o uso da medicação farmacológica que leva à adiçãao poderia ser pensado sob a mesma lógica da toxicomania, exceto pelo fato de se tratar de um produto legalizado pela ciência, aceito socialmente.

Parece claro, portanto, que, para Marcelo, a droga exerce a função de estabilização, tanto pela via do tratamento do gozo do corpo, ${ }^{3}$ quanto pela via da identificação do sujeito a alguns significantes $\left(S_{1}\right)$, como "doidão", "viciado", que podem ser pensados como produção de letras ou signos de gozo. Lacan (1957/2002, p. 498) designa a letra como um "suporte material que o discurso concreto toma emprestado da linguagem". O peso desse suporte material que é a marca-letra sobre o corpo determina "não apenas um laço ou um não laço social, mas também um modo de gozo que provoca um acontecimento de gozo do corpo. Ela é acontecimento de gozo no corpo" (Idaan, 2009, p. 180). Essa marca-letra deixa no corpo "um saber que não comporta o mesmo conhecimento, já que está inscrito num discurso do qual [...] o sujeito [...] não sabe nem o sentido, nem o texto, nem em que língua ele está escrito [...]" (Lacan, 1966/1998, p. 818). Assim, a letra na dimensão de objeto é distinta da letra em sua dimensão significante. Se, por um lado, o texto discursivo tece a combinação entre significantes, a repetição de um signo idêntico a si mesmo, sem combinatória alguma, apenas reproduz o trajeto da satisfação, retornando sempre ao mesmo ponto. Nesse sentido, ele opera como signo de gozo (Idaan, 2009).

No caso de Marcelo, não se trata de uma psicose desencadeada por uso ou abstinência de drogas. A droga entra na vida desse sujeito como um recurso, uma tentativa de autotratamento. No entanto, como discutido anteriormente, um recurso extremamente precário, com consequências devastadoras, tanto do ponto de vista físico e mental, quanto social, pois, além de tudo, o uso da droga o leva a transitar pela marginalidade, colocando-o em situação de risco. Em vista disso, fica a incerteza em relação ao futuro desse sujeito e a dúvida quanto às possibilidades de tratamento, dada a precariedade de recursos simbólicos e a força da

\footnotetext{
Lacan (1972/1973) propõe situar o lugar do gozo, demonstrando que todo gozo efetivo é gozo do Um, isto é, gozo do próprio corpo. Afinal, é sempre o corpo que goza, por qualquer meio que seja. Como afirma Miller (2000, p. 104): "Ele [o sujeito] pode gozar masturbando-se ou simplesmente falando. Pelo simples fato de falar, esse corpo não está ligado ao Outro. Ele está ligado ao seu próprio gozo, seu gozo Uno. [...] Trata-se de tomar a palavra como um modo específico de satisfação do corpo falante". Dessa forma, o gozo do Um pode ser o gozo do próprio corpo, o gozo fálico, gozo da palavra. Em todo caso, não se dirige ao Outro, é sempre o gozo do Um, solto do Outro.
} 
parceria estabelecida com a droga. Tudo gira em torno da droga, até mesmo a iniciativa de procurar a ajuda de uma psicóloga parece ter sido motivada pela esperança em conseguir uma prescrição de Akineton.

\section{Considerações finais}

O termo toxicomania verdadeira, frequentemente usado por autores que pesquisam o tema da droga, refere-se a um uso maníaco, desmedido, sem significação. $O$ uso da droga na psicose também pode se dar de forma maníaca e, nesse caso, poderia ser pensado como uma tentativa falida de localizar o gozo invasivo, sem mediação do falo. Sendo assim, seria possível utilizar o termo toxicomania verdadeira na psicose? $\mathrm{Ou}$ apenas os sujeitos neuróticos seriam verdadeiros toxicômanos?

Parece que, muito mais do que diagnosticar um sujeito como verdadeiro toxicômano, interessa privilegiar a investigação acerca do uso da droga e de sua função na economia psíquica do sujeito. Uma vez que a droga aparece como uma solução encontrada pelo sujeito, cabe investigar as circunstâncias em que esse uso acontece e seus efeitos e, com base nisso, buscar elementos capazes de auxiliar na definição do diagnóstico estrutural, fato fundamental para a condução do tratamento.

O título deste artigo, "Os usos que o psicótico faz da droga", sugere, portanto, que os usos da droga podem ser variados: diferentes usos para diferentes sujeitos. Embora seja possível apreender características comuns aos casos em que a droga se faz presente, deve-se sempre privilegiar a singularidade de cada caso. Dessa forma, é preciso investigar, para além do uso da droga, o uso que o sujeito faz de seu gozo e dos recursos dos quais dispõe.

$\mathrm{Na}$ neurose, o sujeito pode fazer ou não uso do recurso fálico, fazer ou não uso do pai, fazer uso de seu gozo da forma que lhe convém, ainda que isso lhe custe a devastação de seu corpo, como no caso da droga. Na psicose, por sua vez, o sujeito não dispõe da significação fálica e terá que construir ou inventar outros recursos para organizar seu mundo, sua relação com o gozo e com a dimensão irracional do simbólico. A droga aparece aí como uma solução, embora bastante precária por seus efeitos devastadores.

É evidente que o uso da droga não pode ser tratado da mesma forma na neurose e na psicose, e não resta dúvida de que tanto a toxicomania quanto a psicose apresentam impasses em relação ao tratamento. $\mathrm{O}$ 
sujeito adicto a drogas demanda verdadeiramente um trabalho árduo para que algo de sua adição seja, enfim, colocado em palavras, fazendo surgir a demanda de tratamento. Ainda assim, na neurose, existe a aposta de capturar o sujeito pela via da palavra, apontando, ou introduzindo, ou valorizando em seu horizonte semblantes dos quais ele possa fazer uso, desvencilhando-se assim do uso da droga. Trata-se do intento de quebrar a cadeia de repetição de gozo, por meio de algum significante capaz de produzir significação.

Em relação à psicose, o que dizer das possibilidades de tratamento nessa estrutura quando a droga se faz presente? Sabe-se que o psicótico mantém uma relação precária e frágil com a dimensão simbólica, e, assim, sua relação com a palavra se dá de forma totalmente desregulada e singular. O tratamento nesses casos parece ser norteado pela tentativa de romper a identificação do sujeito com a droga. Para isso, no entanto, não existe uma fórmula. $\mathrm{O}$ trabalho é feito caso a caso, com base nas possibilidades que o sujeito apresenta e na escuta e no desejo do analista para conduzir o tratamento. Além disso, deve-se ter sempre em vista que as estabilizações podem se configurar em soluçôes promissoras para o sujeito, quanto mais lhe permitirem a inscrição em algum tipo de discurso ou, rigorosamente falando, em algum tipo de linguagem que possibilite o laço social.

Ainda assim, trata-se de uma tarefa árdua, não só pelos impasses colocados pela própria estrutura psicótica, mas, sobretudo, pela força da parceria estabelecida com a droga na atualidade. $\mathrm{O}$ fato de que um grande número de sujeitos psicóticos tem buscado o recurso da droga comprova que esses sujeitos são também capturados pela oferta sedutora do mercado de consumo. Além disso, a atualidade impõe uma nova realidade à clínica psicanalítica: os novos sintomas neuróticos e as novas manifestações da psicose exigem uma acuidade cada vez maior na definição diagnóstica, assim como o surgimento de novos fenômenos exigem uma reformulação da prática clínica.

Por fim, é preciso salientar que a presença cada vez mais constante da droga na clínica da psicose pode ser pensada como reflexo das mudanças de valores e paradigmas na atualidade. Revela, assim, a complexidade de fatores presentes na clínica da psicose nos dias de hoje, o que póe em prova a definição de diagnósticos e a lógica que rege a direção dos tratamentos. $\mathrm{Na}$ época do "Outro que não existe" (Miler, 2005), da prevalência da lógica do consumo e da globalização, a clínica depara mais um impasse que coloca em evidência a importância de não se perder de vista a primazia da subjetividade e da singularidade. 


\section{Referências}

Beneti, A. (1998). Toxicomania e suplência. In: BENTES, Lenita, GOMES, Ronaldo (org.). O brilho da infelicidade. (pp. 219-227). Rio de Janeiro: Kalimeros.

Carvalho, F. (inédito). A clínica do consumo nas psicoses. Relatório redigido a partir de grupo de trabalho composto por psicanalistas da EBPMG. Belo Horizonte.

Castanet, H. \& De Georges, P. (2004). Enganches, desengaches, reenganches. In: Miller, Jacques-alain. La psicosis ordinária: la convención de Antibes. (pp. 17-43). Buenos Aires: Paidós.

Freud, S. (1996). Uma criança é espancada. In: Edição standard brasileira das obras psicológicas completas de Sigmund Freud. (Jayme Salomão, trad., v. 17, pp. 193-218). Rio de Janeiro: Imago. (Trabalho original publicado em 1919)

Galante, D. \& Naparstek, F. (2008). Monotoxicomaniasy politoxicomanias: la función del tóxico em las psicosis. In: Salamone, Luis Dario et al. Lo inclasificable de las toxicomanias: respuestas del psicoanalisis. (pp. 43-48). Buenos Aires: Grama.

Idaan, C. (2009). Verbete: Letra. In: Scilicet: semblantes e sinthoma. Textos preparatórios para o VII Congresso da Associação Mundial de Psicanálise, Paris, 2010. (pp. 179-181). São Paulo: Escola Brasileira de Psicanálise.

Lacan, J. (1975). Intervenção no encerramento das jornadas de cartéis. Recuperado em junho de 2009, de <http://www.ecolelacaniane.net>.

Lacan, J. (1985). O seminário: livro 20: mais, ainda. (Texto estabelecido por Jacques-Alain Miller, M. D. Magno, versão brasileira). Rio de Janeiro: Jorge Zahar. (Trabalho original publicado em 1972-1973)

Lacan, J. (1998). A instância da letra no inconsciente ou a razão desde Freud. In: Lacan, J. Escritos. (Vera Ribeiro, trad., pp. 496-533). Rio de Janeiro: Jorge Zahar,1998. (Trabalho original publicado em 1966)

Lacan, J. (2002). O seminário: livro 5: as formaçôes do inconsciente. (Texto estabelecido por Jacques-Alain Miller. Vera Ribeiro, trad., Marcus André, rev.). Rio de Janeiro: Jorge Zahar. (Trabalho original publicado em 19571958) 
Laurent, E. (1994). Tres observaciones sobre la toxicomania. In: Sinatra, Ernesto; Sillitti, Daniel; Tarrab, Mauricio (org.). Sujeto, goce y modernidad II. (pp. 8-12). Buenos Aires: Atuel.

Laurent, E. (2004). Como recompor os Nomes-do-pai. Curinga, 20, 17-26.

Laurent, E. (2009). Uso de las neurociências para el psicoanalisis. Ornicar? Digital, 312. Recuperado em novembro de 2009, de <http://www.lacanian. net>.

Maleval, J. et al. (2009). Sobre a fantasia no sujeito psicótico: de sua carência e seus substitutos. In: Besset, Vera Lopes \& CARNEIRO, Henrique Figueiredo (org.). A soberania da clínica na psicopatologia do cotidiano. (pp. 13-44). Rio de Janeiro: Garamond.

Miller, J. A. (1992). Para una investigación sobre el goce autoerótico. In: Sinatra, Ernesto; Sillitti, Daniel; Tarrab, Mauricio (comp.). Sujeto, goce y modernidade: fundamentos de la clínica. (vol. 1, pp. 13-21). Buenos Aires: Atuel-TyA.

Miller, J. A. (2000). Os seis paradigmas do gozo. Opção Lacaniana, 26-27, 87-105.

Miller, J. A. (2005). El Otro que no existe y sus comités de ética (seminário em colaboração com Eric Laurent). Buenos Aires: Paidós.

Naparstek, F. (2005). Introducción a la clínica com toxicomanias y alcoholismo. Buenos Aires: Grama.

Zaffore, C. (2005). Toxicomania e psicoses I. In: Naparstek, F. Introducción a La clínica com toxicomanias y alcoholismo. (pp. 91-107). Buenos Aires: Grama. 